\title{
Paisaje en tránsito. La capital de Aguascalientes durante la primera mitad del siglo XX
}

Resumen: El objetivo del texto es describir y explicar los cambios en el paisaje urbano de la capital del estado de Aguascalientes durante las primeras décadas del siglo XX. Destaco dos elementos: el vínculo de los vecinos con los ríos y estanques de la ciudad, y el nuevo sistema de drenaje. El estudio se basa en tres tipos de fuentes documentales: informes oficiales, quejas de organizaciones vecinales y prensa local. Con esto se demuestran las expectativas y estrategias de los grupos populares al modificar el paisaje. Además, al transformarse el espacio urbano se afectó la vida cotidiana, las relaciones políticas y la lucha por el control de los recursos naturales.

Palabras clave: ríos, drenaje, crecimiento urbano, higiene, contaminación.

\section{Landscape in transit. The capital of Aguascalientes during the first half of the 20th century}

Abstract: This article describes and explains the changes in the urban landscape of the capital of the state of Aguascalientes during the first decades of the 20th century. Two elements are highlighted, the neighbors' relation with the city's rivers and ponds, and the new drainage system. Data for the study comes from three sources: official reports, complaints from neighborhood organizations and local press. The article demonstrates the expectations and strategies of the popular groups when urban landscape was modified. In addition to transforming the urban space, daily life, political relations and the struggle for control of natural resources were affected.

Keywords: rivers, drainage, urban growth, hygiene, pollution.

\section{Paisagem em trânsito. A capital de Aguascalientes durante a primeira metade do século XX}

Resumo: 0 objetivo do texto é descrever e explicar as mudanças na paisagem urbana da capital do estado de Aguascalientes durante as primeiras décadas do século XX. Destaco dois elementos: o vínculo dos vizinhos com os rios e lagoas da cidade, e o novo sistema de drenagem. 0 estudo baseia-se em três tipos de fontes documentais: relatórios oficiais, queixas de organizações de vizinhos e a imprensa local. 0 anterior demonstra as expectativas e estratégias dos grupos populares ao modificarem a paisagem. Adicionalmente, a transformação do espaço urbano afetou a vida cotidiana, as relações políticas e a luta pelo controle dos recursos naturais.

Palavras-chave: rios, drenagem, crescimento urbano, higiene, poluição.

Cómo citar este artículo: Francisco Javier Delgado Aguilar, "Paisaje en tránsito. La capital de Aguascalientes durante la primera mitad del siglo XX”, Trashumante. Revista Americana de Historia Social 16 [2020]: 124-147.

DOI: 10.17533/udea.trahs.n16a07

Fecha de recepción: 21 de enero de 2019

Fecha de aprobación: 6 de septiembre de 2019

Francisco Javier Delgado Aguilar: Doctor en Historia por El Colegio de México. Profesor-investigador adscrito al Centro Universitario de Investigaciones Sociales de la Universidad de Colima.

Correo electrónico: fdelgado@ucol.mx 


\section{Paisaje en tránsito. La capital de Aguascalientes durante la primera mitad del siglo XX}

Francisco Javier Delgado Aguilar

\section{Introducción}

En este texto narro y explico un episodio de la historia de una ciudad en trance Ede acelerado cambio: la capital del estado de Aguascalientes, en México, durante las tres primeras décadas del siglo XX. En el breve lapso de 30 años, en medio de un proceso de industrialización, crecimiento demográfico y expansión urbana desaparecieron los estanques, arroyos y huertas que definieron el paisaje de la ciudad durante todo el siglo XIX. Nuevos y viejos actores sociales se vieron obligados entonces a redefinir sus actividades económicas, sus formas de organización y relaciones con las autoridades locales para adaptarse a las nuevas y cambiantes circunstancias de la ciudad. Al hacerlo, construyeron (y se adaptaron a) un nuevo paisaje urbano. Las circunstancias que propiciaron este cambio, las estrategias de adaptación y la consecuente modificación del espacio son los elementos que considero en la narración de este periodo de la historia de la ciudad de Aguascalientes. ${ }^{1}$

Lo que vivieron la capital y sus habitantes durante estos años fue un episodio común y se consigna en la historia de multitud de centros urbanos de Europa, América Latina y Estados Unidos durante los siglos XIX y XX. Muchas de estas ciudades en crecimiento compartieron características como la llegada de industrias, el aumento de la población y la multiplicación de enfermedades a causa de la contaminación que generaron los nuevos centros fabriles. En varias ciudades la respuesta de las autoridades urbanas fue introducir nuevas tecnologías para renovar la prestación de servicios públicos como el alumbrado, el abasto de agua doméstico y el drenaje, por mencionar solo tres que se relacionaban directamente con el mantenimiento de la higiene pública y la seguridad urbana. La transformación

1. Una primera versión de este artículo se discutió en el Seminario de Historia Política, realizado en el Instituto de Investigaciones Dr. José María Luis Mora. El texto también se benefició ampliamente de las críticas y observaciones de tres dictaminadores anónimos, cuyas observaciones traté de incorporar en la medida de mis posibilidades. 
acelerada y, en algunos casos, radical del paisaje urbano fue una de las múltiples consecuencias de la modernización que experimentaron las ciudades. ${ }^{2}$

El estudio de estos procesos ha generado una cantidad ingente de trabajos planteados desde la historia urbana, la historia social y, más recientemente, la historia ambiental. En el caso de la historia urbana, un punto de partida recurrente fue el tema del reparto, control y consumo de agua, que se abordó a partir de la introducción y gestión de obras y servicios públicos, sus alcances, límites y defectos, así como su significado en cuanto emblemas de la modernidad. Desde esta perspectiva, se ha destacado la acción del Estado y las élites políticas y económicas que, legitimadas por el conocimiento de médicos, ingenieros y arquitectos, emprendieron el camino de la reforma urbana para convertir a las ciudades en espacios limpios, seguros y productivos. ${ }^{3}$

La historia ambiental se ocupó de los efectos de la industrialización en el crecimiento de las ciudades y puso parte de su atención en la contaminación de los ríos provocada por los desechos que transportaban los nuevos sistemas de drenaje. Al centrarse en el vínculo entre ríos y ciudades, hizo evidente los cambios en el paisaje y, sobre todo, las relaciones económicas y de poder entre los actores sociales que orientaron y dieron forma a los nuevos espacios urbanos. ${ }^{4}$

La historiografia de las ciudades mexicanas compartió el interés por la industrialización, el crecimiento urbano y los procesos aparejados que cambiaron el paisaje, como la contaminación y el establecimiento de nuevos servicios públicos. Al igual que en otras latitudes, centró su atención en los conflictos derivados del abasto de agua, principalmente durante el siglo XIX y las primeras décadas del XX. Uno de los dilemas que atrajo la atención de esta literatura sobre las ciudades fue el de la gestión pública enfrentada a la gestión privada del servicio de abasto, el

2. Oriol Nel.Lo y Francesc Muñoz, "El proceso de urbanización”, Geografía humana. Procesos, riesgos e incertidumbres en un mundo globalizado, coord. Joan Romero (Barcelona: Ariel, 2007) 275-354.

3. Algunos ejemplos de este enfoque para los casos de Estados Unidos de América, España e Inglaterra están en: Martin V. Melosi, The Sanitary City. Urban Infrastructure in America from Colonial Times to the Present (Baltimore / London:The John Hopkins University Press, 2000); Martin V. Melosi, Precious Commodity. Providing Water for America's Cities (Pittsburgh: University of Pittsburgh Press, 2011); Juan Manuel Matés-Barco, La conquista del agua. Historia económica del abastecimiento urbano (Jaén: Universidad de Jaén, 1999); John Broich, London: Water and the Making of the Modern City (Pittsburgh: University of Pittsburgh Press, 2013). Para las ciudades latinoamericanas y chinas se pueden consultar los siguientes artículos de Sofia Luzuriaga Jaramillo, "Abastecimiento de aguas y políticas de saneamiento en Quito, 1880-1930”, Procesos. Revista Ecuatoriana de Historia 32.2 (2010):31-56; Álvaro León Casas Orrego, "Los circuitos del agua y la higiene urbana en la ciudad de Cartagena a comienzos del siglo XX”, História, Ciências, Saúde-Manguinhos 7.2 (2000):347-375; Liu Haiyan, "Water Supply and the Reconstruction of Urban Space in Early Twentieth-century Tianjin", Urban History 38.3 (2011):391-412.

4. Ejemplos de cómo la historia ambiental ha abordado los procesos de cambio urbano e industrialización en ciudades como París, Londres, Estrasburgo, Milán, Nantes, Düsseldorf y Bogotá se encuentran en Dieter Schott y otros, Resources of the City: Contributions to an Environmental History of Modern Europe (Abindgdon, Oxon: Routledge, 2016); Martin Knoll y otros, Rivers Lost, Rivers Regained: Rethinking City-River Relations (Pittsburgh: University of Pittsburgh Press, 2017). 
establecimiento de empresas privadas y su relación con los gobiernos locales y la creciente injerencia del Estado central en los usos del agua en las ciudades. El tema del drenaje y la contaminación de los ríos ha recibido menos atención, sobre todo durante el siglo XX, cuando los efectos de la polución derivaron en la entubación y desaparición de ríos en varias ciudades de México. ${ }^{5}$

El trabajo que aquí presento se inscribe en esta literatura sobre las ciudades y trata de realizar conexiones entre la historia social, la ambiental y la urbana mediante el estudio de los ríos y estanques que rodeaban la ciudad y desaparecieron en medio de la expansión urbana que ocurrió en Aguascalientes en las primeras décadas del siglo XX. Uso como referente el término de paisaje, entendido no solo como una representación o forma de ver el mundo, sino también como la organización del espacio que resulta de las relaciones de poder, económicas y culturales establecidas entre los actores urbanos. De estas relaciones se derivan conflictos que influyen en la configuración de la ciudad, sus cambios y permanencias. Visto así, abordo el tema del drenaje, los ríos y estanques en la ciudad de Aguascalientes como un mirador para explicar, desde una perspectiva diferente, las transformaciones que sufrió la capital del estado de Aguascalientes en las primeras décadas del siglo XX. ${ }^{6}$

Inicio el texto con la descripción del impacto de la industrialización en la ciudad a finales del siglo XIX y principios del XX. Después narro la desecación del estanque de La Cruz que se ubicaba al norte de la capital y era un elemento clave del paisaje urbano y la infraestructura hidráulica. Enseguida presento los avatares de la instalación del primer sistema de drenaje y la oposición que produjo su introducción y expansión. Termino con la historia que antecedió a la desaparición del arroyo de Los Caleros que corría al sur de la ciudad. En cada episodio considero los objetivos, argumentos, intereses y formas de movilización

5. Juan Manuel Matés-Barco y José Juan Pablo Rojas-Ramírez, coords., Agua y servicios públicos en España y México (Jaén: Editorial Universidad de Jaén, 2018); Julio Contreras-Utrera y otros, Agua, Estado y sociedad en América Latina y España (Xalapa: Consejo Superior de Investigaciones Científicas / Escuela de Estudios Hispanoamericanos, 2015); Carlos Lira Vásquez y Ariel Rodríguez Kuri, coords., Ciudades mexicanas del siglo XX. Siete estudios históricos (México: El Colegio de México / Universidad Autónoma Metropolitana-Azcapotzalco, 2009); Diana Birrichaga Gardida, coord., La modernización del sistema de agua potable en México 1810-1950 (México: El Colegio Mexiquense, 2007); Blanca Estela Suárez Cortez, coord., Historia de los usos del agua en México. Oligarquías, empresas y ayuntamientos (1840-1940) (México: Comisión Nacional del Agua / Centro de Investigaciones y Estudios Superiores en Antropología Social / IMTA, 1998). La introducción y funcionamiento del sistema de drenaje en las ciudades mexicanas del siglo XX ha sido menos estudiados que el del abasto de agua. Dos excepciones son los estudios de Christina Jiménez y Daniel Newcomer para las ciudades de Morelia y León, respectivamente. Véase Christina M. Jiménez, "Popular Organizing for Public Services: Residents Modernize Morelia, Mexico, 1880-1920", Journal of Urban History 30.4 (2004): 495-518; Daniel Newcomer, "The Symbolic Battleground: The Culture of Modernization in 1940s León, Guanajuato", Mexican Studies / Estudios Mexicanos 18.1 (2002): 61-100.

6. El término de paisaje se retoma de las ideas y planteamientos generales de dos autores: Denis E. Cosgrove, Social Formation and Symbolic Landscape (Londres: University of Wisconsin Press, 1998); Don Mitchell, Cultural Geography. A Critical Introduction (Londres: Blackwell Publishing, 2000). 
de los grupos urbanos que se enfrentaron por el control y explotación de los arroyos. También destaco la injerencia de las autoridades locales y federales, cuyas decisiones influyeron en el desenlace de estos conflictos y en el rumbo que tomó la configuración del paisaje en la capital de Aguascalientes durante la primera mitad del siglo XX.

\section{La ciudad de Aguascalientes en el cambio de siglo}

En la década de 1880, cualquier visitante que observara la ciudad de Aguascalientes notaría la avasalladora presencia de huertas y arroyos que envolvían la capital por sus cuatro puntos cardinales y configuraban el paisaje urbano, las actividades económicas y la vida cotidiana de sus habitantes. El cultivo de huertas había definido la fisonomía de la ciudad por lo menos desde el siglo XVII y para fines del XIX la rodeaban por el poniente (el rumbo del barrio de San Marcos), al sur (en los barrios de Triana y La Salud) y en el oriente, que, además del llamado barrio de Texas, albergaba los manantiales del Ojocaliente, fuente principal de abasto de agua de los horticultores. Hacia 1880, las huertas funcionaban como espacios de convivencia y eran vistas como un factor positivo para la higiene pública. ${ }^{7}$

Los arroyos también tenían una impronta fundamental en el paisaje urbano. Como se muestra en la Figura 1, en el norte se encontraba el de Los Arellano y el estanque de La Cruz, en donde se almacenaba el agua destinada al riego de las huertas del barrio de San Marcos. Hasta mediados del siglo XX ambos cuerpos de agua marcaron los límites de la ciudad, que por aquel rumbo era habitada por artesanos y comerciantes que daban vida al llamado barrio de Guadalupe. Por el sur, muy cerca de la plaza principal, corrían los arroyos de El Cedazo y Los Caleros que también funcionaban como frontera urbana, pues más allá de los ríos se ubicaban los barrios de Triana y La Salud, ocupados principalmente por huertas. ${ }^{8}$

Era común que los horticultores se enfrentaran por el agua de regadío proveniente del manantial del Ojocaliente, pero no parece que hayan existido conflictos graves entre los usos agrícolas e industriales. El hecho se explica porque antes de 1880 la actividad fabril estuvo dominada por tenerías, obrajes y molinos que obtenían de los arroyos el agua necesaria para sus procesos productivos. ${ }^{9}$ Esta situación

7. Jesús Gómez Serrano, “'Remansos de ensueño’. Las huertas y la gestión del agua en Aguascalientes, 1855-1914”, Historia Mexicana 64.3 (2015): 1001-1097; Eduardo J. Correa, Un viaje a Termápolis (México: Instituto Cultural de Aguascalientes, 1992) 105-110.

8. Jesús Gómez Serrano y Francisco Delgado Aguilar, Aguascalientes. Historia breve (México: Fondo de Cultura Económica / El Colegio de México, 2010) 261-264.

9. Jesús Gómez Serrano, Aguascalientes en la historia, 1786-1920. Los embates de la modernidad, t. 2 (México: Instituto de Investigaciones Dr. José María Luis Mora, 1988) 125-207. Antes de la llegada de la Fundición y los Talleres, fábricas textiles como La Purísima, San Ignacio y La Aurora recurrían al agua de ríos y manantiales y depositaban sus desechos en el curso de las corrientes. Véase AGMA, Aguascalientes, Fondo Histórico, caja 240, exp. 24; AHEA, Aguascalientes, Fondo Poder Ejecutivo, Sección Secretaría General de Gobierno, caja 139, exp. 6; El Republicano (Aguascalientes) 15 de enero de 1899. 
Figura 1. La ciudad de Aguascalientes a principios del siglo XX

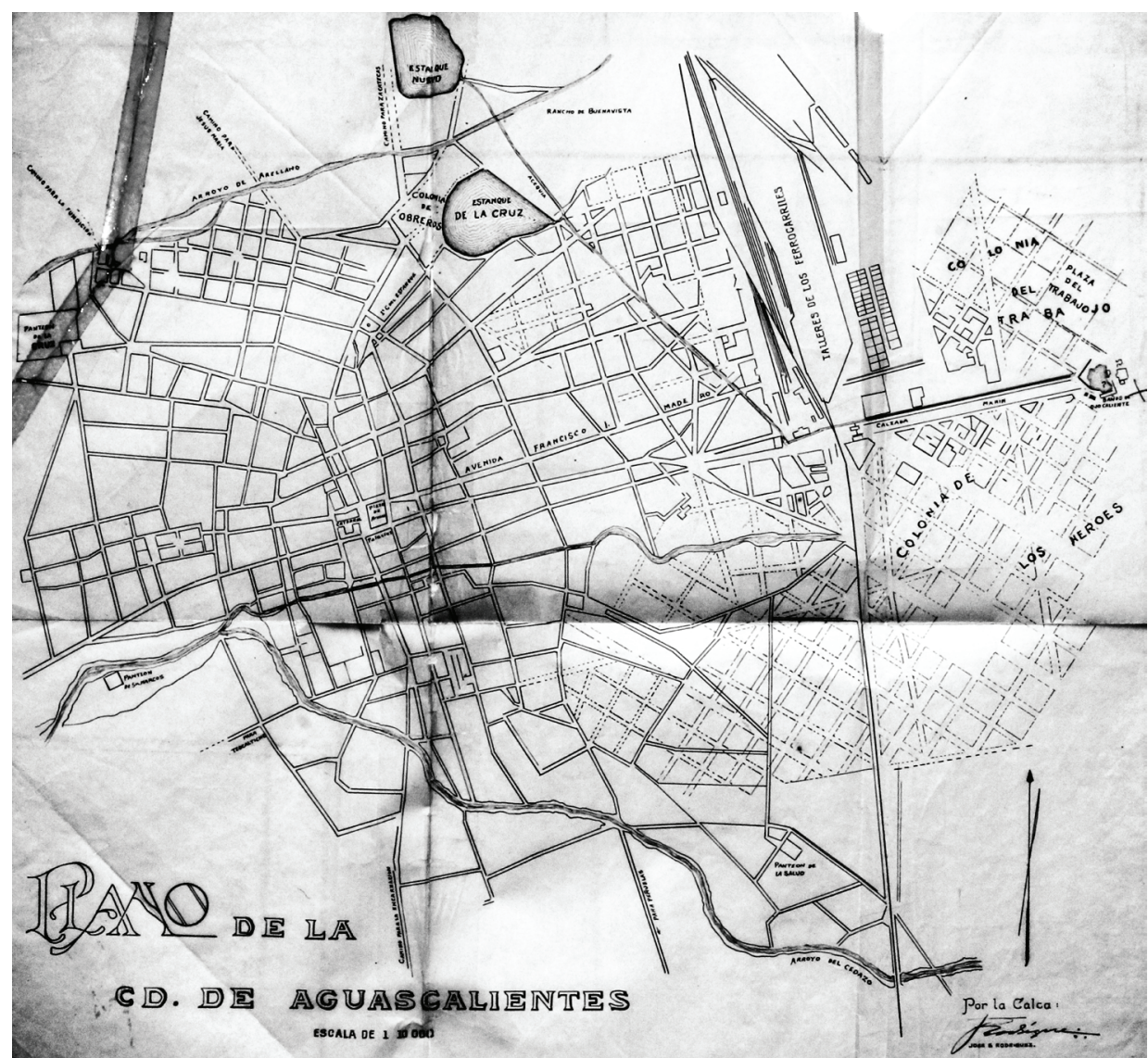

Fuente: AHA, México, Aprovechamientos Superficiales, caja 285, exp. 6832.

cambió drásticamente con la instalación de dos grandes fábricas de capital extranjero: la Fundición Central Mexicana (1894) y los Talleres de Reparación del Ferrocarril Central Mexicano (1903).

Ambas factorías reactivaron la economía, contribuyeron al surgimiento de una fuerza de trabajo industrial, modificaron el paisaje, impulsaron el crecimiento urbano y el aumento de la población. ${ }^{10}$ Esto fue notorio sobre todo al oriente en donde los Talleres propiciaron la apertura de calles, la instalación de líneas para tranvías y el surgimiento de fábricas y edificios, como la fábrica de harina y almidones La Perla, una fábrica de hielo perteneciente a Hugo Clegg, el edificio de la Compañía de Luz y Fuerza, una fundición de fierro y bronce propiedad de Luis B.

10. Jesús Gómez Serrano, Aguascalientes en la historia, 1786-1920. Sociedad y cultura, vol. 1, t. 3 (México: Instituto de Investigaciones Dr. José María Luis Mora, 1988) 67, 70; Gerardo Martínez Delgado, "Cambio y proyecto urbano. Aguascalientes, 1880-1914" (Tesis de maestría en Historia, Pontificia Universidad Javeriana, 2006) 230, 231, 258, 271, 296. 
Lawrence y el Hotel Escobedo. ${ }^{11}$ Un fenómeno similar ocurrió en la parte norponiente en donde se levantó la Fundición Central Mexicana en 1895: se abrieron calles, surgieron comercios y barrios como el de Guadalupe se revitalizaron gracias al arribo de personas que buscaban trabajo en las nuevas industrias. ${ }^{12}$

La estructura ocupacional también cambió. Aunque no se tienen datos acerca de la distribución de ocupaciones en la ciudad o el municipio de Aguascalientes para los años de 1900 o 1910, cuando la Fundición ocupara hasta 2,400 trabajadores entre 1906 y 1907 y los Talleres emplearan a más de 2,000 personas, da una idea de la creciente importancia del sector industrial dentro de la estructura socioprofesional de la ciudad a principios del siglo XX. A lo anterior habría que añadir los 400 trabajadores que laboraban en La Perla, mientras que la fundición de fierro y talleres mecánicos ocupaba una cantidad similar de obreros. ${ }^{13}$ La nueva fuerza de trabajo se agrupó en colonias populares como la Buenavista, Héroes y del Trabajo - en el oriente-, mientras que en el poniente se formaron la colonia México y la del Carmen. En varios casos, los asentamientos se formaron sobre terrenos que habían sido ocupados por huertas y, durante mucho tiempo, carecieron de los servicios de luz, agua y drenaje, como ocurrió en la colonia Gremial. ${ }^{14}$

La revolución de 1910 provocó una oleada de violencia, inestabilidad política y movilización social que interrumpió el desarrollo industrial y comercial de la ciudad y el estado. Los efectos de la lucha armada fueron evidentes por lo menos desde 1913, cuando la región se vio envuelta en una espiral de inflación, desabasto y epidemias. Las cosechas se perdieron, los campos no se cultivaron, las actividades minera y comercial se paralizaron. Al no encontrar empleo, muchos campesinos abandonaron sus pueblos y otros se unieron a las tropas de bandidos y revolucionarios que proliferaban en el campo. ${ }^{15}$

A partir de 1920, finalizado el periodo más violento de la revolución, la actividad económica tendió a recuperarse, aunque el proceso fue muy lento y lleno

11. Jesús Bernal Sánchez, Apuntes históricos, geográficos y estadísticos del estado de Aguascalientes (Aguascalientes: Imprenta de Alberto E. Pedroza, 1928) 325, 326.

12. Gómez Serrano, Aguascalientes en la historia 1786-1920. Sociedad y cultura 95, 96; Bernal Sánchez 50, 51; Martínez Delgado 280; Antonio Salazar Sánchez, El Aguascalientes de antaño (1920-1960) (México: Instituto Cultural de Aguascalientes, 2003) 49, 50; Heliodoro Martínez López, El Aguascalientes que yo conocí (Aguascalientes: Imprenta de Daniel Méndez Acuña, 1978) 101, 102, 109.

13. Alfonso Luis Velasco, Geografía y estadística de la República Mexicana, Aguascalientes, t. XVII (México: Secretaría de Fomento, 1889) 93, 95, 110; Rodrigo Espinosa, Directorio de Aguascalientes (Aguascalientes: Imprenta El Lápiz Rojo, 1908) 12, 13; José Llamas Flores, Geografía particular del estado de Aguascalientes (Aguascalientes: Imprenta Unión de Mecánicos, 1924) 24; Gómez Serrano, Aguascalientes en la historia 1786-1920. Los embates de la modernidad 125-141,161-207.

14. Gómez Serrano, Aguascalientes en la historia 1786-1920. Sociedad y cultura 70,72-86, 91,92; Salazar Sánchez 49; Martínez Delgado 244, 249-257; Llamas Flores 34, 35; Fernando I. Salmerón Castro, Intermediarios del progreso. Política y crecimiento urbano en Aguascalientes (México: Instituto Cultural de Aguascalientes / Centro de Investigaciones y Estudios Superiores en Antropología Social, 1998) $57,58,82,83$.

15. Gómez Serrano y Delgado Aguilar 205-215. 
de obstáculos. En 1925, por ejemplo, la Fundición Central cerró sus puertas y se trasladó a San Luis Potosí con el argumento de que no contaba con la suficiente materia prima para mantener en funcionamiento la fábrica. ${ }^{16}$ Golpes como este frenaron la incipiente industrialización, pero no el crecimiento urbano, lo que derivó en una presión inusitada sobre servicios públicos como el drenaje y el abasto de agua. ${ }^{17}$

A la par del crecimiento de la capital, se consolidó y divulgó entre grupos e instituciones urbanas la aspiración a vivir en una ciudad moderna, lo que significaba, entre otras cosas, introducir y ampliar servicios públicos como el alumbrado, el drenaje y el abasto de agua para usos domésticos; todo en aras de mejorar la limpieza y seguridad de los espacios urbanos. La justificación de esta política derivaba de los postulados del paradigma higiénico de los miasmas, que atribuía la propagación de epidemias y enfermedades a las pestilencias y malos olores que generaban el estancamiento del agua y del aire. Esta convicción estuvo en la base de múltiples políticas orientadas a mejorar los sistemas de abasto de agua y drenaje y evitar la creación y multiplicación de charcos y agua estancada con materia orgánica en descomposición. ${ }^{18}$

En las últimas décadas del siglo XIX el paradigma de los miasmas fue desplazado por el bacteriológico, que señaló al consumo de agua contaminada con microorganismos y bacterias como la causa de los brotes epidémicos de cólera y fiebre amarilla y de enfermedades intestinales y diarreicas. A partir de este descubrimiento fue ineludible realizar estudios químicos y bacteriológicos que ayudaran a identificar si el agua estaba libre de microbios, materias orgánicas y sustancias minerales que la contaminaban. En la práctica cotidiana los actores urbanos mezclaban las ideas de ambos paradigmas para denunciar lugares contaminados o inseguros, como ocurrió con el estanque de La Cruz.

\section{El estanque de la Cruz: crecimiento urbano y cambio de paisaje}

Con una superficie de 61,300 metros cuadrados y capacidad para almacenar hasta 104,145 metros cúbicos de agua, el estanque de La Cruz era parte importante del paisaje al norte de la capital. Su principal función era irrigar las huertas de San Marcos y los jardines de Zaragoza y Guadalupe. En algunos casos, el agua era aprovechada por alfarerías del norte de la población. En el estanque, los vecinos se reunían, bañaban, paseaban o se abastecían de agua para hacer adobes o dar de beber al ganado. ${ }^{19}$

16. Jesús Gómez Serrano, Aguascalientes: imperio de los Guggenheim (México: Fondo de Cultura Económica, 1982) 360-372.

17. Gómez Serrano, Aguascalientes en la historia, 1786-1920. Sociedad y cultura 68-94.

18. Alain Corbin, El perfume o el miasma. El olfato y lo imaginario social. Siglos XVIII y XIX (México: Fondo de Cultura Económica, 2002).

19. AGMA, Aguascalientes, Fondo Histórico, caja 747, exp. 24. 
En su libro testimonial sobre la vida urbana en la primera mitad del siglo XX, Heliodoro Martínez López lo recuerda como un "pequeño lago artificial [...] rodeado de frondosos mezquites que formaban una especie de alameda". Cada domingo asistían "cantidad de familias humildes (que) organizaban paseos, comiendo a la sombra de los árboles". Otros recorrían el lugar a pie o en bicicleta y algunos optaban por los paseos en lancha a través de las "aguas verdosas y agitadas" del estanque, como se ilustra en la Figura 2. Martínez López aseguraba incluso que el "pequeño lago" aliviaba las altas temperaturas durante la primavera y el verano, pues "templaba el caluroso clima de nuestra ciudad". ${ }^{20}$

Figura 2. El estanque de La Cruz

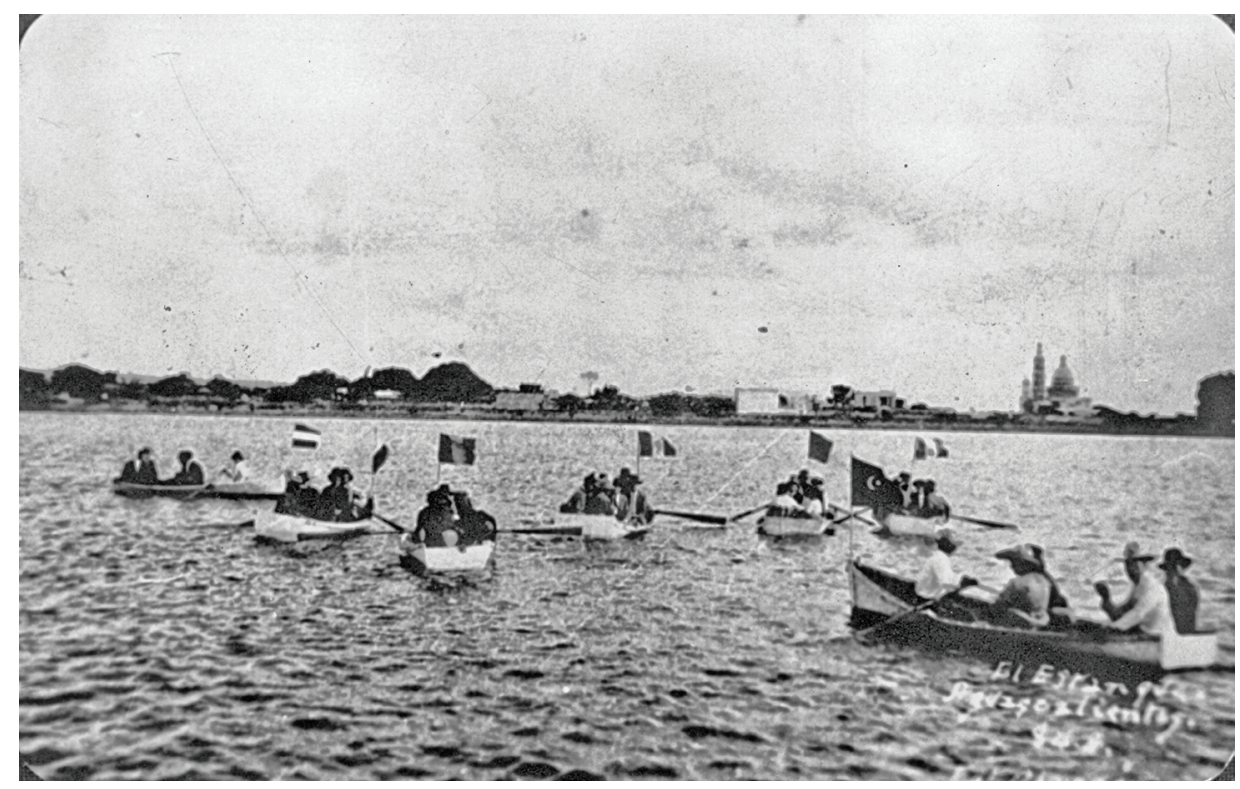

Fuente: "Paseo dominical en lanchas en el estanque de La Cruz". AHEA, Aguascalientes, Fondo Fototeca, Sección Jaime Torres Bodet, n. 37.

Paralela a esta valoración, existían otras que destacaban los peligros del estanque para la seguridad y la higiene públicas. ${ }^{21}$ En 1910, por ejemplo, vecinos del rumbo denunciaron la existencia de baldíos utilizados para depositar "toda clase de inmundicias y desechos". Esto perjudicaba la salud pública, "la cual se ve seriamente amenazada con la propagación de enfermedades infecto-contagiosas que posiblemente pudiera ocasionar el acumulamiento de las materias antes citadas". ${ }^{22}$

20. Martínez López 14, 15.

21. AGMA, Aguascalientes, Fondo Histórico, caja 844, exp. 5, f. 15.

22. AGMA, Aguascalientes, Fondo Histórico, caja 447, exp. 16. 
Fue a inicios de la década de 1940 cuando las quejas se multiplicaron y encontraron eco entre las autoridades estatales. En sendos escritos de febrero y noviembre de 1941, colonos del barrio de Zaragoza pidieron al gobernador del estado y al presidente municipal la supresión inmediata del estanque de La Cruz, pues se había convertido en "lugar de reunión de toda clase de viciosos, ya que su absoluta oscuridad es muy apropiada para ello”. Lo más grave era que el otrora lugar de paseo y recreación era ya un "foco de infección, origen de las gripas, infecciones intestinales, paludismos, tifoideas que continuamente asolan este barrio”. Según los vecinos,

nuestras familias y personas se están viendo amenazadas por las enfermedades que tiene su origen en la humedad que ha invadido nuestras moradas, como el paludismo que cada día se extiende en esta población, por la misma humedad que en toda la zona o alrededores de este depósito se estila, y por lo tanto en nuestros hogares se vive en una situación que ya es insoportable, tanto por los miasmas que despiden las aguas estancadas y contaminadas por las suciedades de los baños de 'Ojo Caliente' que este depósito recoge, como el mismo efecto que produce el calor del sol en los residuos que quedan en esas mismas aguas, cuando son desalojadas completamente de su vaso. ${ }^{2.3}$

Para no perjudicar a los horticultores, los vecinos del barrio de Zaragoza proponían que el agua se depositara en el llamado "Estanque Nuevo", ubicado más hacia el norte, que no se utilizaba y con el cual se aportaría a los horticultores el mismo servicio. Además, planteaban que, una vez cegado el estanque, el espacio se aprovechara "en un uso o servicio laudable, ya sea urbanizándolo o bien utilizarlo de algún modo que sea siempre una garantía para la estabilidad, salubridad e higiene personal de los habitantes de esta población". ${ }^{24}$

El diagnóstico de las autoridades encargadas de la higiene pública en la capital reforzó las demandas de los inconformes. En enero de 1942, un reporte del jefe de los Servicios Sanitarios Coordinados en Aguascalientes señalaba que, debido al crecimiento urbano, el estanque de La Cruz "ya no se encuentra propiamente en la orilla de la ciudad sino circundado por habitaciones y casas que cada día van aumentando". Esto lo había convertido en un "foco insalubre", debido a que los vecinos depositaban "animales muertos, basuras e inmundicias que con el sol y el polvo se traducen en fermentaciones y putrefacciones a la salud colectiva". 25 "Para higienizar el barrio o rumbo de la ciudad", continuaba el funcionario, era necesario construir fuentes de ornato y sembrar árboles del mismo tipo. La solución radical consistía en impulsar "un fraccionamiento apropiado para la construcción de casas saludables y rodeadas de jardines y arboleda", con lo que se proporcionaría a la ciudad "un centro higienizante y benéfico que correspondería a la obligación de la autoridad municipal de velar por los intereses de la ciudad y de hermosearla y 
embellecerla para beneficio público". ${ }^{26}$ Sabedor de que la desecación del estanque implicaba cancelar buena parte del riego que recibían las huertas de la ciudad, el jefe de los Servicios Sanitarios proponía limitar el regadío “a las huertas frutales, impidiendo que se utilice para el riego de hortalizas y consiguiendo de esta manera suprimir definitivamente el inconveniente de usar aguas sucias para el riego de hortalizas".

Los horticultores de la ciudad se opusieron tenazmente a la intención de desecar el estanque, por lo que las quejas de los vecinos y los reportes oficiales fueron el inicio de un largo y complicado litigio entre el ayuntamiento, que buscaba la desecación del estanque, y la Liga de Horticultores, que se opuso terminantemente a dicha medida con el argumento de que disminuiría el menguante abasto de agua dedicado al riego de huertas. Ambas partes recurrieron al arbitrio del gobierno central que en 1946 a través de la Secretaría de Agricultura y Fomento (SAF) decidió no reclamar la propiedad del estanque.

El retiro del gobierno federal permitió que el congreso local autorizara al cabildo "la venta de los terrenos de su propiedad ocupados por el llamado Estanque Viejo o de La Cruz, ubicados al poniente de la Colonia Gremial Ferrocarrilera y que ha venido poseyendo a título de propiedad desde tiempo inmemorial". Los terrenos deberían destinarse "precisamente a ser urbanizados mediante fraccionamiento" y "el producto que reciba el municipio por la venta de estos bienes se destinará precisamente al financiamiento de obras públicas del ayuntamiento de la ciudad y en beneficio de la misma y de modo especial al arreglo y embellecimiento de la Calzada de la Revolución", ${ }^{27}$

La desecación del estanque de La Cruz ilustra el cambio en el paisaje que provocaron la industrialización y el crecimiento urbano. Como protagonistas del conflicto aparecen en primer lugar los vecinos de las recién construidas colonias, nuevos actores urbanos que mostraron un alto grado de capacidad organizativa para presentar sus demandas ante las autoridades locales y enfrentar a los horticultores, que se oponían a la desaparición de una de sus principales fuentes de abasto de agua para regadío. También se debe resaltar la presencia del ayuntamiento, cuya intervención fue posible gracias a que el gobierno federal no reclamó jurisdicción alguna sobre el destino del estanque. Gracias a esta decisión, el cabildo dispuso la desecación para favorecer los reclamos higienistas y las necesidades domésticas de una creciente población urbana, en detrimento de los intereses y usos agrícolas que hasta inicios del siglo XX habían definido la distribución del líquido.

De esta forma, los vecinos de las colonias populares participaron activamente en la transformación de la capital con miras a convertirla en un entorno higiénico y seguro. Esto implicaba la desaparición de estanques que como el de La Cruz pasaron de ser referentes de la organización del espacio, lugares de convivencia y

26. AHEA, Aguascalientes, Fondo Poder Ejecutivo, Sección Secretaría General de Gobierno, caja 472, leg. 5 , exp. 5.

27. Periódico Oficial (Aguascalientes) 11 de agosto de 1946. 
fundamento de varias actividades económicas, a significar una amenaza que era necesario suprimir en aras de conservar la higiene y la moral pública.

Aunque la desaparición del estanque de La Cruz significó un golpe mortal para las ya decadentes huertas, la Liga de Horticultores sobrevivió hasta 1969. En marzo de dicho año, el gerente general de la Secretaría de Recursos Hidráulicos informaba sobre "algunos problemas dentro de la Unión de Horticultores, por motivo del riego de huertas". Para estas fechas, ya solo existían cultivos en el sur de la ciudad, pues como lo indicaba el gerente de la secretaría, habían desaparecido "con motivo de la transformación de la ciudad". ${ }^{28}$ La razón de esta supervivencia puede encontrarse en las consecuencias de la introducción y funcionamiento del sistema de drenaje urbano, proceso que nos remite a la limitada capacidad de gestión del ayuntamiento de la capital y a las consecuencias imprevistas de la innovación tecnológica en la modificación del paisaje urbano.

\section{La experiencia del primer sistema de drenaje: innovación tecnológica y contaminación urbana}

El primer sistema centralizado de drenaje de la ciudad de Aguascalientes se construyó en 1923. Hasta entonces, los desechos urbanos se gestionaron de forma particular, irregular y fragmentaria. Algunos vecinos tenían en sus viviendas resumideros o pozos absorbentes para depositar las aguas sucias de baños y demás usos domésticos. Otros habían construido caños que salían de sus casas y llevaban los desechos a las zanjas hechas en la calle para dicho propósito. La mayoría simplemente tiraban las aguas negras en las banquetas. ${ }^{29}$ Estas prácticas ocasionaron múltiples quejas de autoridades, habitantes y periodistas, quienes durante las primeras décadas del siglo XX denunciaron reiteradamente la multiplicación de pantanos y charcos de aguas negras, que al producir miasmas se convertían en focos de infección y contribuían a la propagación de enfermedades que amenazaban la salud pública. ${ }^{30}$

Las autoridades locales encargaron la construcción del nuevo sistema de drenaje a la compañía Jas F. Martin. Según informes oficiales, para 1923 había instalados 3,044 metros lineales de tubería de barro vitrificado, 1,352 correspondientes al colector principal y 1,692 para colectores laterales. El drenaje fue de tipo combinado, pues mezclaba aguas negras y pluviales y abarcó los principales jardines, plazas y edificios de la ciudad, así como las calles más céntricas.

28. AHA, México, Aprovechamientos Superficiales, caja 285, exp. 6832, ff. 305-306.

29. Francisco Javier Delgado Aguilar, Jefaturas políticas. Dinámica política y control social en Aguascalientes, 1867-1911 (México: Gobierno del estado de Aguascalientes / Universidad Autónoma de Aguascalientes, 2000) 234.

30. El Republicano (Aguascalientes) 26 de diciembre de 1867; El Clarín (Aguascalientes) 23 de diciembre de 1911; El Clarín (Aguascalientes) 13 de enero de 1912; La Opinión (Aguascalientes) 18 de abril de 1935; AHEA, Aguascalientes, Fondo Poder Ejecutivo, Sección Secretaría General de Gobierno, caja 462, leg. 8, exp. 1. 
El costo fue de $\$ 23,179$ y se pagó con aportaciones del poder ejecutivo, el ayuntamiento y de los propietarios beneficiados por las obras, a quienes por disposición del congreso se cobró una cuota única de tres pesos "por cada metro cuadrado de pavimento correspondiente al perímetro comprendido en el frente de cada propiedad, limitado por los extremos de la misma, la banqueta y la mitad de la calle". El gobierno federal se comprometió a pagar por el drenaje instalado en todos los "edificios nacionales" y fincas intervenidas. ${ }^{31}$

El decreto del congreso y la ejecución de las obras causaron descontento entre los propietarios de fincas. Según reporte del ingeniero Francisco Reitter, encargado de supervisar los trabajos, era común escuchar "voces en el público" que aseguraban que la pavimentación y el drenaje eran "inservibles", aunque - según el ingeniero- dicha afirmación se hacía sin "ninguna base científica”. Para contrarrestar esta oposición el gobierno emprendió una labor de propaganda y cabildeo que incluyó anuncios en la prensa y diversas reuniones con los dueños de casas obligados a pagar cuotas. No obstante, la resistencia y las críticas continuaron y solo "después de muchos esfuerzos hubo de aplicarse por fin el decreto porque voluntariamente había sido imposible llevar a la práctica dicha obra”. Una vez concluido, el drenaje fue administrado conjuntamente por el poder ejecutivo local, el ayuntamiento y una junta especial de mejoras materiales. ${ }^{32}$

El nuevo sistema no tuvo efectos positivos en el corto plazo. Para septiembre de 1925, según reportaba el cónsul norteamericano radicado en Aguascalientes, el drenaje necesitaba reparaciones urgentes y las autoridades municipales no encaraban el problema. El funcionario norteamericano sostenía que los desechos se recolectaban de forma inadecuada y se depositaban al aire libre a las afueras de la ciudad. ${ }^{33}$ En las décadas de 1930 y 1940 se amplió el drenaje en condiciones similares a las de 1923: se llamó a contratistas para que ejecutaran los trabajos, se decretaron contribuciones forzosas a los propietarios (que se ampararon ante el poder judicial para no cubrirlas) y se organizaron juntas de administración alternas al ayuntamiento para gestionar el servicio. ${ }^{34}$

31. Según el gobernador Rafael Arellano Valle, la Federación aportó 26,000 pesos, “que por la penuria del Erario Federal, se convino en cubrirla en timbres de contribución federal y que se venderían, como se está haciendo, por cuenta del Estado". Rafael Arellano Valle, Informe que el ejecutivo del estado de Aguascalientes rinde a la H. Legislatura de conformidad con lo mandado por la constitución local y contestación del C. diputado José Luis Macías, presidente del H. Congreso del Estado (Aguascalientes: Imprenta de Ricardo Rodríguez Romo e Hijos, 1924) 32, 33.

32. Los datos sobre las obras de drenaje y pavimentación se encuentran en: AHEA, Aguascalientes, Fondo Poder Ejecutivo, Sección Secretaría General de Gobierno, caja 137, exp. 1; Bernal Sánchez 120-122.Véase también el periódico Renacimiento (Aguascalientes) 21 de enero de 1923, en donde como parte de la propaganda mencionada se incluía la frase: "Ayude con su simpatía a la pavimentación y drenaje de la ciudad".

33. NAW, Washington, State of Department, Serie 812000/27621.

34. AGMA, Aguascalientes, Fondo Histórico, caja 581, exp. 2; AGMA, Aguascalientes, Fondo Histórico, caja 1003, exp. 1, f. 104; AGMA, Aguascalientes, Fondo Histórico, caja 946, exp. 7, ff. 19, 49; AGMA, Aguascalientes, Fondo Histórico, caja 946, exp. 7, f. 20; AGMA, Aguascalientes, Fondo 
Estas intervenciones fueron parciales e insuficientes para desaparecer las "cloacas malsanas y peligrosas para la salud pública" que aparecían alrededor de edificios públicos con conexiones deficientes, como el cuartel y el hospital militar. Además, el sistema carecía de "corrientes de agua que hagan la limpia de las cañerías", pues dependía para su abastecimiento de los manantiales del Ojocaliente. ${ }^{35}$

A pesar de las deficiencias y la oposición, hubo propietarios y vecinos que buscaron incorporarse a la red de drenaje, y se organizaron para realizar y pagar por su cuenta los trabajos de conexión, previa autorización del ayuntamiento. ${ }^{36}$ Cuando el sistema fallaba, ya fuera por deficiencias técnicas o por falta de agua, eran estos nuevos usuarios los primeros en pedirle al cabildo que arreglara las tuberías o sancionara a los establecimientos que depositaban los desechos en la vía pública. Los argumentos de los inconformes para justificar estas demandas se inspiraban en el paradigma miasmático, pues aseguraban que los sempiternos charcos y pantanos que anegaban las calles eran focos de infección que provocaban hedores insoportables y epidemias. ${ }^{37}$

La intervención de los vecinos en la expansión del drenaje no es un dato menor. Indica, en primer lugar, un cierto nivel de organización ciudadana necesario para presionar al ayuntamiento y obligarlo a cumplir con la tarea de reparar y extender la red de drenaje o, en su defecto, emprender por su cuenta las obras; tarea que demandaba juntar firmas para presentar la petición ante el cabildo, recolectar dinero para ejecutar los trabajos, comprar material y contratar mano de obra. Por otro lado, la participación vecinal apunta al hecho de que autoridades y ciudadanos podían compartir los objetivos de saneamiento y modernización urbana que justificaban la introducción y ampliación de servicios públicos como el del drenaje. ${ }^{38}$

Alrededor de este proyecto (compartido y debatido) de modernización y del cambio del paisaje urbano se desarrollaron conflictos que trascendieron el desacuerdo sanitario y remiten al problema del acceso y control de recursos naturales. La disputa alrededor de las aguas del (contaminado) arroyo de Los Caleros es un ejemplo relevante de esta clase de enfrentamientos en los que se mezclaban ideas e

Histórico, caja 1073, exp. 11, f. 2; AGMA, Aguascalientes, Fondo Histórico, caja 990, exp. 11, f. 234; Diario del Centro (Aguascalientes) 28 de octubre de 1930; Enrique Osornio, Informe que rinde el C. Enrique Osornio Camarena, gobernador Constitucional del Estado, a la H. Legislatura del mismo, de conformidad con lo mandado por la fracción II del artículo 41 de la constitución política local, y contestación que el C. Diputado Gonzalo Macías, presidente del H. Congreso del Estado, da al C. Gobernador del mismo, en relación con su informe administrativo, rendido el 16 de septiembre de 1936 (Aguascalientes: Imprenta Rodríguez Romo, 1936) 27, 28.

35. Renacimiento (Aguascalientes) 16 de marzo de 1924; La Opinión (Aguascalientes) 19 de enero de 1928; AGMA, Aguascalientes, Fondo Histórico, caja 946, exp. 7, f. 148; AGMA, Aguascalientes, Fondo Histórico, caja 566, exp. 89; AGMA, Aguascalientes, Fondo Histórico, caja 599, exp. 25.

36. AGMA, Aguascalientes, Fondo Histórico, caja 592, exp. 8; AGMA, Aguascalientes, Fondo Histórico, caja 1003, exp. 1, f. 108; AGMA, Aguascalientes, Fondo Histórico, caja 946, exp. 7, f. 21.

37. Alborada (Aguascalientes) 10 de abril de 1934; AHEA, Aguascalientes, Fondo Poder Ejecutivo, Sección Secretaría General de Gobierno, caja 462, leg. 8, exp. 1.

38. Jiménez 500-506. 
intereses sobre la higiene pública, las actividades económicas, el cambio del paisaje urbano y las relaciones de poder.

\section{El arroyo de Los Caleros, la huerta Gámez y las aguas del albañal}

Una de las consecuencias más evidentes del funcionamiento del sistema de drenaje fue la contaminación del arroyo de Los Caleros, que se convirtió en el principal albañal de la capital. Esta corriente nacía en unos lomeríos situados a tres kilómetros al oriente de la ciudad, en terrenos de la hacienda del Ojocaliente. Atravesaba la capital de oriente a poniente, pasaba al sur de la plaza principal para desembocar en el arroyo de El Cedazo y unirse luego al río San Pedro en su margen izquierda.

A principios del siglo XX ambos arroyos orientaban y frenaban la expansión urbana. El de Los Caleros dificultaba el crecimiento hacia el sur y era una especie de división entre el centro y los barrios de Triana y La Salud, que aparecían segregados del resto de la capital. ${ }^{39}$ Alimentado con sobrantes del manantial del Ojocaliente, gozaba de la fama de tener aguas claras y abundantes y en su cauce había canales, norias y bordos para irrigar pequeños ranchos y huertas ubicadas en las cercanías. En la zona existían además fábricas de ladrillo que usaban las tierras ribereñas como materia prima (Figura 3). ${ }^{40}$

Figura 3. Paisaje al oriente de la ciudad. En primer plano, una fábrica de ladrillos

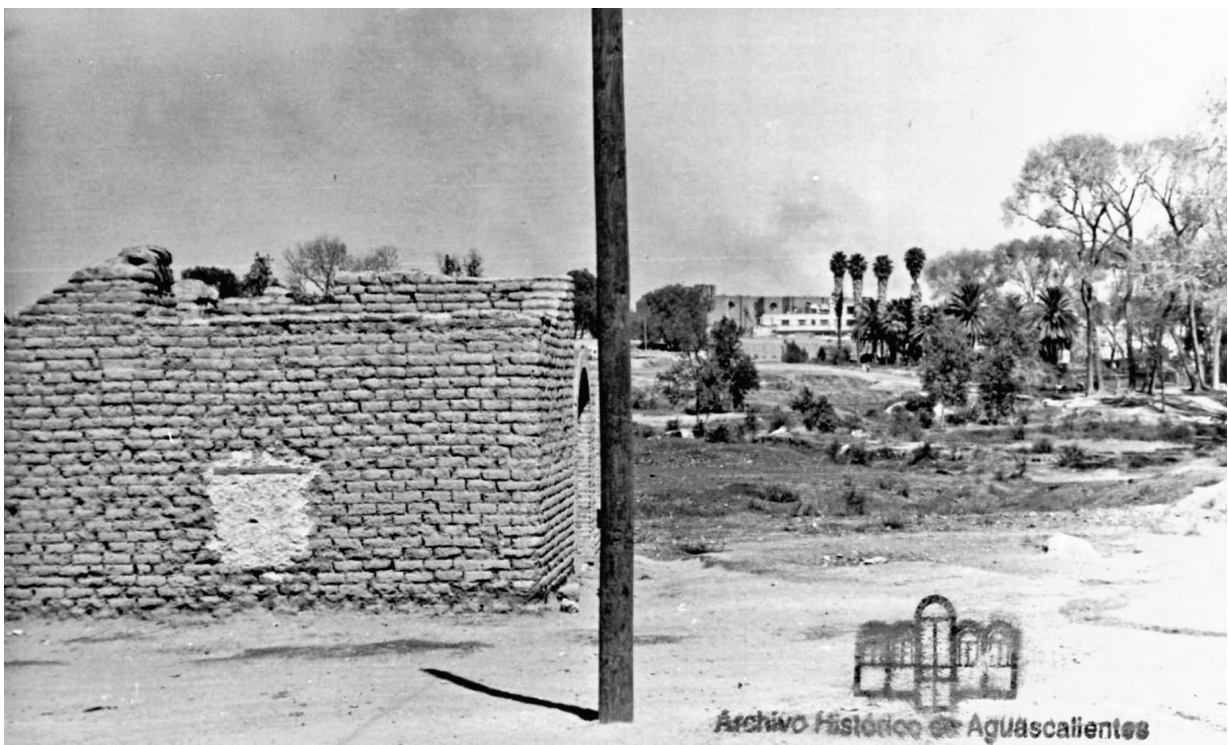

Fuente: AHEA, Aguascalientes, Fondo Fototeca, Sección Luis Ortega, n. 163.

39. Salazar Sánchez 49.

40. AHA, México, Aprovechamientos Superficiales, caja 285, exp. 6836, f. 13; AHA, México, Aprovechamientos Superficiales, caja 285, exp. 6836, ff. 77-81. 
Desde fines del siglo XIX, el arroyo de Los Caleros recibía los desechos de viviendas y comercios, de la cárcel pública y el cuartel de infantería. Según informes oficiales y publicaciones de la época, eran las "miasmas insalubres que se desprenden a cada momento de materias fecales y de aguas descompuestas que corren lentamente por falta de nivel y de limpieza en el arroyo" las que provocaban "la mayor parte de las fiebres que reinan en la ciudad". ${ }^{41}$ Para combatir esta situación, el ayuntamiento entubó una parte del cauce del arroyo en 1890 y luego otra en 1918, un año después de que una epidemia de tifo asolara la ciudad. En aquella ocasión, el presidente municipal calificó la obra como una medida de "higiene y cultura" que favorecería tanto "la salubridad pública como el ornato". ${ }^{42}$

No obstante, el mismo ayuntamiento permitió que establecimientos como el hotel Francia, los Talleres del Ferrocarril y la fábrica de harina La Perla depositaran sus desechos en el arroyo. En el caso de La Perla que desechaba agua con gluten - "cuya descomposición produce una fetidez insoportable"-, el resultado fue que en una extensa zona de la capital comenzó a percibirse "intensamente el pésimo olor de los desechos que arrastra" el arroyo. ${ }^{43}$

La contaminación del arroyo se agravó con la instalación del drenaje, pues "los desfogues de los colectores no caen directamente a la masa de agua de la corriente, de suyo muy pequeña [...] sino que la boca de salida de esos colectores queda, en muchos casos, a varios metros de altura de la lámina de agua, resultando que los desechos y residuos caen sobre los taludes del arroyo y forman promontorios de inmundicia". ${ }^{44}$ De esta forma, las aguas cristalinas del arroyo fueron desplazadas por las aguas negras del drenaje, lo que obligó a los horticultores a adaptarse a los efectos de la polución.

El arroyo de Los Caleros se explotaba con propósitos agrícolas por los menos desde fines del siglo XIX, cuando María del Refugio Orozco solicitó al ayuntamiento el uso de las aguas para regar algunas huertas de su propiedad. Obtenido el permiso, Orozco construyó un bordo con tres compuertas hecho de mampostería de piedra y tablones de madera. Este bordo comenzó a ser conocido como presa Gámez, pues junto con las huertas pasó a manos de Rafael y Edmundo Gámez, sobrinos de la señora María del Refugio. Ambos mejoraron el sistema de riego e instalaron norias y bombas para elevar el agua y regar las partes más elevadas de sus terrenos. Para lidiar con la contaminación, represaban el agua durante más tiempo "a fin de que sufra una ligera decantación, yéndose al fondo del depósito las materias pesadas que acarrea en suspensión el agua y a la superficie libre de ésta las ligeras, formándose una capa gruesa de chapopote que es removida de cuando en

41. AGMA, Aguascalientes, Fondo Histórico, caja 171, exp. 44; AGMA, Aguascalientes, Fondo Histórico, caja 174, exp. 20; El Republicano (Aguascalientes) 28 de septiembre de 1890.

42. AGMA, Aguascalientes, Fondo Histórico, caja 451, exp. 8.

43. AHA, México, Aprovechamientos Superficiales, caja 285, exp. 6836, ff. 77-81; AHA, México, Aprovechamientos Superficiales, caja 285, exp. 6836, ff. 122-129.

44. AHEA, Aguascalientes, Fondo Poder Ejecutivo, Sección Secretaría General de Gobierno, caja 315, exp. 10. 
cuando". Con estos procedimientos, los Gámez pusieron en pie una de las huertas más grandes de la ciudad, pues hacia la década de 1940 contaba con alrededor de dos mil árboles "tanto frutales como de forestación". ${ }^{45}$

Varios horticultores ubicados aguas abajo del arroyo siguieron el ejemplo y construyeron bordos y pequeñas presas de derivación. Así las cosas, aunque para la década de 1930 se prohibió el cultivo de hortalizas debido a la contaminación del arroyo, todavía hacia 1938 se consignaba la existencia de huertas de árboles frutales (chabacanos, ciruelos, duraznos, granados, manzanos, perales e higueras), plantas florales (alcatraz, rosales, claveles y palmas), maíz y alfalfa. ${ }^{46}$

El cultivo de huertas convivía con la explotación de yacimientos de cal, ubicados en los terrenos adyacentes al arroyo. Las noticias de esta actividad se remontan a 1888, año en el que Jesús Díaz de León consignó la existencia de terrenos con "gruesas capas de caliza arcillosa" que eran utilizadas para fabricar loza blanca y adobes, "artículos de primera necesidad en los materiales de construcción de esta ciudad”. Según afirmaba Díaz de León, los alfareros extraían la caliza "desde tiempo inmemorial" y para fines de la década de 1880 esta actividad era "una de las principales industrias de la población".

A inicios del siglo XX el crecimiento de la ciudad y la construcción de casas impulsaron la sobreexplotación de los yacimientos más ricos en cal, ubicados entre la estación del ferrocarril y los manantiales del Ojocaliente. Los trabajos de extracción (que realizaban trabajadores conocidos como "caleros") se trasladaron entonces a la ribera del río del arroyo de Los Caleros, en terrenos de la hacienda del Ojocaliente. Las excavaciones ganaron en amplitud y profundidad, hasta abarcar un área de aproximadamente 60,000 metros cuadrados. Se volvió común entonces que brotaran aguas freáticas que dificultaban obtener la cal, y como no se había tenido la precaución de construir bordos para evitar derramamientos, las horadaciones llegaron hasta el lecho del arroyo y modificaron su cauce. ${ }^{47}$

La convivencia de actividades alrededor del arroyo y la contaminación de la corriente exacerbada por la introducción del drenaje originaron múltiples conflictos entre horticultores y caleros. El principal motivo de desacuerdo fue la presencia de presas y bordos en el cauce del arroyo que los horticultores construían para aprovechar las abundantes aguas negras que el drenaje depositaba en la corriente. Los caleros denunciaron esta práctica como una amenaza a la salud pública

45. AHEA, Aguascalientes, Fondo Poder Ejecutivo, Sección Secretaría General de Gobierno, caja 461, leg. 1, exp. 10.

46. AHA, México, Aprovechamientos Superficiales, caja 285, exp. 6836, ff. 77-81; AHA, México, Aprovechamientos Superficiales, caja 285, exp. 6836, ff. 122-129; Martínez López 127, 128.

47. Jesús Díaz, “Apuntes para el estudio de la higiene de Aguascalientes por el Doctor Jesús Díaz de León, con la colaboración del Doctor Manuel Gómez Portugal", Memoria que sobre los diversos ramos de la administración pública presenta a la honorable legislatura el C. Alejandro Vázquez del Mercado, gobernador constitucional del Estado de Aguascalientes por el periodo de $1^{\circ}$ de diciembre de 1887 a 30 de noviembre de 1891 (Aguascalientes: Tipografia de Jesús Díaz de León, 1892) 182, 183; AHA, México, Aprovechamientos Superficiales, caja 285, exp. 6836, ff. 122-129. 
y demandaron la destrucción de los bordos, principalmente el conocido como presa Gámez. Inició así un debate que incluyó quejas, denuncias en la prensa local, estudios y diagnósticos, muchos de ellos contradictorios, sobre el impacto de los aprovechamientos del arroyo de Los Caleros en la salud pública (Figura 4).

Figura 4. Fábrica de ladrillos ubicada junto al cauce del arroyo

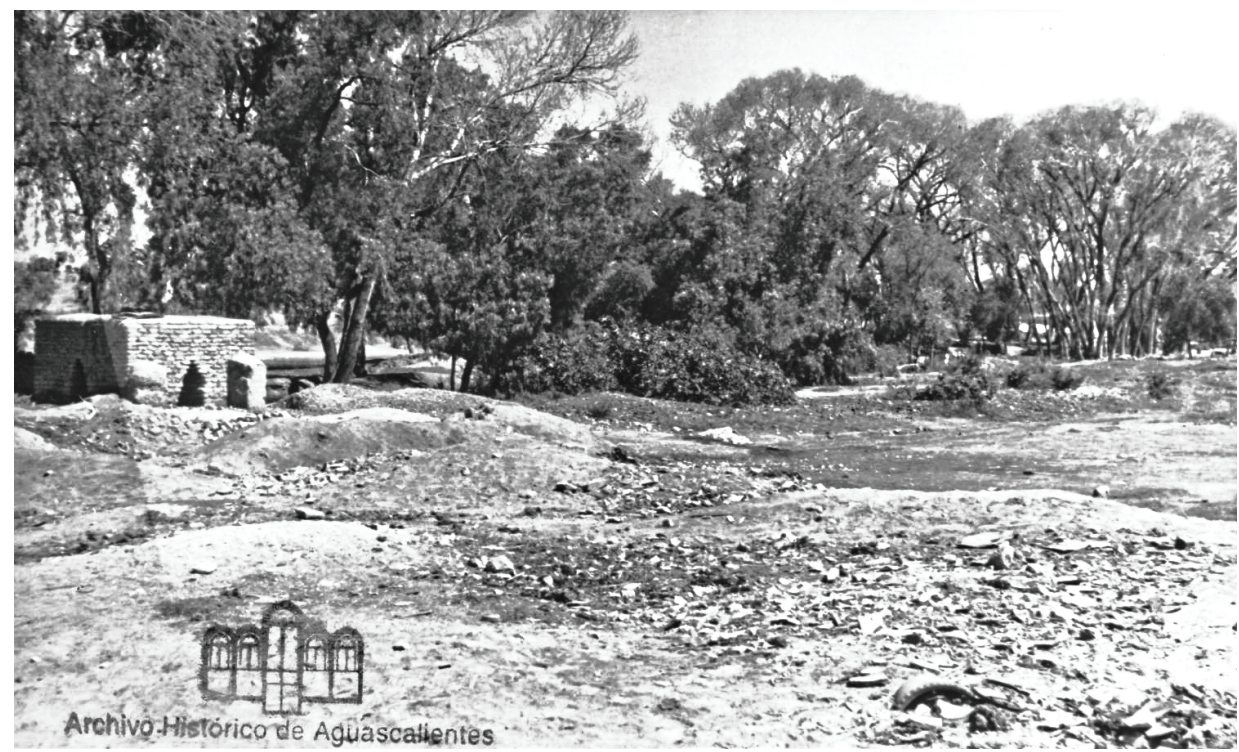

Fuente: AHEA, Aguascalientes, Fondo Fototeca, Sección Luis Ortega, n. 185.

Los opositores a los bordos y presas sostenían que estancar las aguas negras del arroyo favorecía la multiplicación de moscos y zancudos que propagaban enfermedades como el paludismo en todo el sureste de la capital, principalmente, en vecindades de colonias populares como San Luis, Héroes y del Trabajo. ${ }^{48}$ En cambio, los defensores de los bordos les atribuían una doble utilidad. Por una parte, al represar el agua acumulaban un caudal que se liberaba periódicamente y contaba con la presión suficiente para lavar el arroyo, hecho que favorecía la salud pública de la ciudad. Además, permitían el cultivo de huertas, fuente de trabajo y sostén de "numerosas familias de peones". Afirmaban también que el agua almacenada contenía aceite y petróleo que impedía el nacimiento de zancudos, por lo que los bordos y represas no podían ser considerados como un foco de infección. De hecho, era en los pantanos y charcos que se formaban por las excavaciones de los caleros en donde surgían y se multiplicaban los moscos tan temidos. ${ }^{49}$

48. Alborada (Aguascalientes) 22 de diciembre de 1933.

49. AGMA, Aguascalientes, Fondo Histórico, caja 776, exp. 37; Alborada (Aguascalientes) 27 de diciembre de 1933. 
El enfrentamiento entre horticultores y caleros requirió la intervención del gobierno federal, que envió a dos ingenieros para evaluar la situación y proponer soluciones. El primero de ellos, Miguel N. Rodríguez, entregó un informe fechado en 1933. En el documento, Rodríguez apoyaba la versión de los caleros y afirmaba que las represas perjudicaban la salud pública de la ciudad al producir "fermentaciones" y permitir que los horticultores regaran cultivos con aguas "cargadas de microbios de diversas enfermedades, entre las cuales la tifoidea ocasiona muy graves males en Aguascalientes". Para acabar con el problema, el ingeniero Rodríguez recomendaba mejorar el drenaje, obligar a las industrias a tratar sus aguas residuales y destruir las represas para que los horticultores "buscaran nuevos sistemas de irrigación". 50

Cinco años después, en julio de 1938, el gobierno federal ordenó una nueva inspección, que corrió a cargo del ingeniero Romualdo Godínez. Godínez adoptó los argumentos de los horticultores y sostuvo - en contraste con el informe de su colega Rodríguez - que los bordos y represas, lejos de perjudicar la salud pública, contribuían a limpiar el arroyo, pues permitían los "golpes que agua por medio de los cuales se lava la parte más baja del arroyo en donde desembocan los drenajes de la ciudad". Además, afirmaba Godínez, los horticultores no regaban hortalizas con el agua del drenaje, sino únicamente árboles frutales, plantas florales y cereales, por lo que no contaminaban los alimentos. Finalmente, aseguraba que el riego permitía mantener una extensa área arbolada que beneficiaba a la ciudad. En su informe, el ingeniero negaba que las presas produjeran "olores fétidos" o fueran criaderos de mosquitos transmisores del paludismo y señalaba las excavaciones de los caleros como la causa de la formación de charcos y pantanos de aguas negras. ${ }^{51}$

Además de informes contradictorios, el gobierno federal recibió quejas del Sindicato Único de la Construcción, organización que los trabajadores de la cal crearon en 1938 para demandar la destrucción de bordos y presas en el arroyo de Los Caleros. El Sindicato denunció con los argumentos ya conocidos el sistema de riego que los horticultores habían construido para aprovechar las aguas negras: perjudicaba la salud pública al contribuir a la aparición frecuente de enfermedades palúdicas e intestinales, principalmente entre los trabajadores de cal que, ignorantes, pobres y desnutridos, eran presa fácil de las enfermedades endémicas. El principal responsable de esta situación era, según el sindicato, Rafael Gámez, “capitalista ambicioso" que contribuía a la multiplicación de casos de tifoidea al vender en el mercado las legumbres contaminadas de su huerta. Además, con la influencia que le daba el dinero, Gámez deseaba establecer un "monopolio de la cal” y desplazar al resto de los trabajadores afiliados al sindicato. ${ }^{52}$

50. AHA, México, Aprovechamientos Superficiales, caja 285, exp. 6836, ff. 77-81.

51. AHA, México, Aprovechamientos Superficiales, caja 285, exp. 6836, ff. 122-129.

52. AHA, México, Aprovechamientos Superficiales, caja 285, exp. 6836, ff. 117-121v; AHEA, Aguascalientes, Fondo Poder Ejecutivo, Sección Secretaría General de Gobierno, caja 461, leg. 1, exp. 10. 
Rafael Gámez se defendió de las acusaciones en una carta dirigida al presidente Manuel Ávila Camacho el 4 de agosto de 1941. En la misiva, denunciaba ataques en contra de su presa — que incluían incendios provocados intencionalmente aprovechando la presencia de petróleo en el agua_-, y los atribuía a la actividad de "agitadores políticos" que apoyaban las exigencias de los caleros a cambio de votos en las elecciones locales. Por esta razón pedía "que este negocio se solucione de una vez por todas, que no esté yo con la zozobra de que cada vez que se avecinan elecciones, tenga a mi edad que andar implorando otra vez que se revisen los fallos que ya existen". ${ }^{53}$

A pesar de las quejas y peticiones, la evidencia disponible indica que la situación del arroyo de Los Caleros no cambió en los siguientes años: las principales fábricas y talleres de la ciudad depositaban sus residuos al arroyo sin darles un tratamiento adecuado; las presas y bordos utilizadas para el riego de huertas seguían activas y la "insoportable fetidez" se convirtió en un elemento sustancial de la vida cotidiana de los habitantes, sobre todo en las noches de verano, cuando el calor y el viento agravaban y extendían la pestilencia. ${ }^{54}$ En 1943, según el periódico Provincia, el presidente municipal había inspeccionado el arroyo hasta llegar a "unos charcos de agua estancadas que en estas épocas de calores se llenan de mosquitos" que propagaban "con toda rapidez y eficacia un cúmulo de enfermedades. Como en ocasiones anteriores, las autoridades habían "girado órdenes" para sanear la zona, "esperándose que la cooperación de los vecinos sea efectiva, pues es en provecho de todos en general, pero particularmente de ellos, que son los más afectados". ${ }^{55}$

\section{Conclusiones}

Reportes oficiales, quejas ciudadanas y artículos de la prensa local pueden dar la impresión de que la situación en los alrededores del arroyo de Los Caleros no cambió desde 1890. Sin embargo, si atendemos con mayor cuidado a las circunstancias del contexto, resulta evidente que el paisaje de la ciudad se modificó aceleradamente a lo largo de la primera mitad del siglo XX. El cambio estuvo acompañado - y propiciado - por profundas transformaciones en la economía, la política, la estructura social y la representación de la ciudad.

En Aguascalientes la llegada de grandes fábricas y establecimientos industriales fue el detonante de la transformación. A partir de 1890, la ciudad creció en número de habitantes y surgieron colonias populares, principalmente al norte y oriente. El segundo efecto evidente e inmediato de la industrialización y la expansión urbana fue la contaminación de los arroyos y estanques que rodeaban la ciudad, así como una renovada competencia por el control de la distribución del agua, que hasta entonces se había destinado preferentemente para la irrigación de huertas.

53. AHEA, Aguascalientes, Fondo Poder Ejecutivo, Sección Secretaría General de Gobierno, caja 461, leg. 1, exp. 10.

54. AHA, México, Aprovechamientos Superficiales, caja 285, exp. 6836, ff. 84-89, 106-112.

55. Provincia (Aguascalientes) 1 de junio de 1943. 
Los nuevos grupos sociales, sobre todo trabajadores y grupos populares, debieron adaptarse a un entorno adverso: barrios y colonias sucias, inseguras y en las que era complicado satisfacer necesidades básicas como el abasto de agua para usos domésticos. Era, además, un espacio que cambiaba con inusitada rapidez: lo que antes eran arroyos y estanques en donde los vecinos se reunían para convivir y reconocerse comenzaron a convertirse en amenazas para la salud y la seguridad públicas.

En esta coyuntura, los vecinos de las colonias populares mostraron gran capacidad para protestar y encontrar un lugar en el proceso de transformación del paisaje urbano. En sus demandas, mezclaron valores, ideas y argumentos provenientes de dos paradigmas sanitarios: el de los miasmas y el bacteriológico. Aunque con el paso de los años ganaron terreno las ideas del paradigma bacteriológico — que apuntaban sus baterías hacia los microbios y moscos como elementos propagadores de las enfermedades - lo que predominó entre la prensa y las sociedades de colonos fue el viejo paradigma miasmático, que atribuía el deterioro de la higiene urbana a los vapores y la fetidez que resultaban de la contaminación de los arroyos.

Un ejemplo de este proceso fue la desecación del estanque de la Cruz, que los vecinos de las nuevas colonias populares surgidas al norte de la ciudad demandaron y obtuvieron con argumentos inspirados en el paradigma sanitario de los miasmas. La desecación golpeó fuertemente los intereses de los horticultores, quienes sobrevivieron gracias al arroyo de Los Caleros, cuyo caudal aumentó debido a las aguas negras depositadas por el sistema de drenaje.

Incapaces de negociar con las fábricas o de obligarlas a tratar sus desechos antes de depositarlos en los cauces de los arroyos, las autoridades locales impulsaron la instalación de una red de drenaje, innovación tecnológica que resultó insuficiente para evitar o al menos controlar la descarga de aguas negras. Lo que se logró fue abrir una faceta inesperada en el panorama de las disputas por el control de los usos del agua, pues los horticultores comenzaron a aprovechar las aguas negras que contaminaban los arroyos, lo que fue evidente sobre todo en el caso de Los Caleros. Como se describió líneas arriba, para la década de 1930 esta práctica ocasionó conflictos entre horticultores, colonos y trabajadores dedicados a la extracción de cal.

Aunque la contaminación del arroyo se remontaba a principios del siglo XX, el contexto en el que transcurrió el enfrentamiento era radicalmente diferente. En primer lugar, se debe considerar que tanto la contaminación como la explotación de los yacimientos de cal habían modificado profundamente el paisaje al punto de cambiar incluso el cauce del arroyo. Además, los argumentos relacionados con el paradigma de los miasmas estaban siendo desplazados por la propagación de ideas sanitarias relacionadas con el paradigma bacteriológico. Finalmente, los actores involucrados recurrieron a nuevas formas de asociación y acción política, como la organización sindical e incluso el uso dosificado de la violencia. Todos estos son indicios de la influencia que tuvo el proceso de crecimiento urbano y la industrialización en la reconfiguración del paisaje, la vida cotidiana y la lucha por el control de los recursos naturales en Aguascalientes durante la primera mitad del siglo XX. 


\section{Fuentes}

\section{Manuscritas}

Archivo Histórico del Agua, México (AHA)

Fondo Aprovechamientos Superficiales

National Archives of Washington, Washington (NAW)

Serie 812000

Archivo General Municipal de Aguascalientes, Aguascalientes (AGMA)

Fondo Histórico

Archivo Histórico del Estado de Aguascalientes, Aguascalientes (AHEA)

Fondo Poder Ejecutivo, Sección Secretaría General de Gobierno

Fondo Fototeca, Sección Jaime Torres Bodet y Luis Ortega

\section{Impresas}

Arellano Valle, Rafael. Informe que el ejecutivo del estado de Aguascalientes rinde a la $H$. Legislatura de conformidad con lo mandado por la constitución local y contestación del C. diputado José Luis Macías, presidente del H. Congreso del Estado. Aguascalientes: Imprenta de Ricardo Rodríguez Romo e Hijos, 1924.

Bernal Sánchez, Jesús. Apuntes históricos, geográficos y estadísticos del estado de Aguascalientes. Aguascalientes: Imprenta de Alberto E. Pedroza, 1928.

Díaz de León, Jesús. “Apuntes para el estudio de la higiene de Aguascalientes por el Doctor Jesús Díaz de León, con la colaboración del Doctor Manuel Gómez Portugal". Memoria que sobre los diversos ramos de la administración pública presenta a la honorable legislatura el C. Alejandro Vázquez del Mercado, gobernador constitucional del Estado de Aguascalientes por el periodo de $1^{\circ}$ de diciembre de 1887 a 30 de noviembre de 1891. Aguascalientes:Tipografia de Jesús Díaz de León, 1892.

Espinosa, Rodrigo. Directorio de Aguascalientes. Aguascalientes: Imprenta El Lápiz Rojo, 1908.

Osornio, Enrique. Informe que rinde el C. Enrique Osornio Camarena, gobernador Constitucional del Estado, a la H. Legislatura del mismo, de conformidad con lo mandado por la fracción II del artículo 41 de la constitución política local, $y$ contestación que el C. Diputado Gonzalo Macías, presidente del H. Congreso del Estado, da al C. Gobernador del mismo, en relación con su informe administrativo, rendido el 16 de septiembre de 1936. Aguascalientes: Imprenta Rodríguez Romo, 1936.

Vázquez del Mercado, Alejandro. Memoria que sobre los diversos ramos de la administración pública presenta a la honorable legislatura, el ciudadano Alejandro Vázquez del Mercado, gobernador constitucional del estado de Aguascalientes por el periodo de $1^{\circ}$ de diciembre de 1887 a 30 de noviembre de 1891. Aguascalientes: Tipografia de J. Díaz de León a cargo de Ricardo Rodríguez Romo, 1892.

Velasco, Alfonso Luis. Geografía y estadística de la República Mexicana, Aguascalientes. Tomo XVII. México: Secretaría de Fomento, 1889. 


\section{Periódico y revistas}

Alborada (Aguascalientes) 1933-1934.

El Clarín (Aguascalientes) 1911-1912.

Diario del Centro (Aguascalientes) 1930.

La Opinión (Aguascalientes) 1928, 1935.

Periódico Oficial (Aguascalientes) 1946.

Provincia (Aguascalientes) 1943.

Renacimiento (Aguascalientes) 1923, 1924.

El Republicano (Aguascalientes) 1867, 1890, 1899.

\section{Bibliografía}

Birrichaga Gardida, Diana. Coord. La modernización del sistema de agua potable en México 1810-1950. México: El Colegio Mexiquense, 2007.

Broich, John. London: Water and the Making of the Modern City. Pittsburgh: University of Pittsburgh Press, 2013.

Casas Orrego, Álvaro León. "Los circuitos del agua y la higiene urbana en la ciudad de Cartagena a comienzos del siglo XX”. História, Ciências, SaúdeManguinhos 7.2 (2000): 347-375.

Contreras-Utrera, Julio y otros. Agua, Estado y sociedad en América Latina y España. Xalapa: Consejo Superior de Investigaciones Científicas / Escuela de Estudios Hispanoamericanos, 2015.

Corbin, Alain. El perfume o el miasma. El olfato y lo imaginario social. Siglos XVIII y XIX. México: Fondo de Cultura Económica, 2002.

Correa, Eduardo J. Un viaje a Termápolis. México: Instituto Cultural de Aguascalientes, 1992.

Cosgrove, Denis E. Social Formation and Symbolic Landscape. Londres: University of Wisconsin Press, 1998.

Delgado Aguilar, Francisco Javier. Jefaturas políticas. Dinámica política y control social en Aguascalientes, 1867-1911. México: Gobierno del estado de Aguascalientes / Universidad Autónoma de Aguascalientes, 2000.

Gómez Serrano, Jesús. Aguascalientes: imperio de los Guggenheim. México: Fondo de Cultura Económica, 1982.

. Aguascalientes en la historia 1786-1920. Los embates de la modernidad.Tomo 2. México: Instituto de Investigaciones Dr. José María Luis Mora, 1988. . Aguascalientes en la historia 1786-1920. Sociedad y cultura.Volumen 1. Tomo 3. México: Instituto de Investigaciones Dr. José María Luis Mora, 1988. . “'Remansos de ensueño'. Las huertas y la gestión del agua en Aguascalientes, 1855-1914”. Historia Mexicana 64.3 (2015): 1001-1097.

Gómez Serrano, Jesús y Francisco Delgado Aguilar. Aguascalientes. Historia breve. México: Fondo de Cultura Económica / El Colegio de México, 2010.

Haiyan, Liu. "Water Supply and the Reconstruction of Urban Space in Early Twentieth-century Tianjin". Urban History 38.3 (2011): 391-412. 
Jiménez, Christina M. “Popular Organizing for Public Services: Residents Modernize Morelia, Mexico, 1880-1920”. Journal of Urban History 30.4 (2004): 495-518.

Knoll, Martin y otros. Rivers Lost, Rivers Regained: Rethinking City-River Relations. Pittsburgh: University of Pittsburgh Press, 2017.

Lira Vásquez, Carlos y Ariel Rodríguez Kuri. Coords. Ciudades mexicanas del siglo XX. Siete estudios históricos. México: El Colegio de México / Universidad Autónoma Metropolitana-Azcapotzalco, 2009.

Llamas Flores, José. Geografía particular del estado de Aguascalientes. Aguascalientes: Imprenta Unión de Mecánicos, 1924.

Luzuriaga Jaramillo, Sofia. “Abastecimiento de aguas y políticas de saneamiento en Quito, 1880-1930". Procesos. Revista Ecuatoriana de Historia 32.2 (2010): 31-56.

Martínez Delgado, Gerardo. "Cambio y proyecto urbano. Aguascalientes, 1880-1914”. Tesis de maestría en Historia, Pontificia Universidad Javeriana, 2006.

Martínez López, Heliodoro. El Aguascalientes que yo conocí. Aguascalientes: Imprenta de Daniel Méndez Acuña, 1978.

Matés-Barco, Juan Manuel. La conquista del agua. Historia económica del abastecimiento urbano. Jaén: Universidad de Jaén, 1999.

Matés-Barco, Juan Manuel y José Juan Pablo Rojas-Ramírez. Coords. Agua y servicios públicos en España y México. Jaén: Editorial Universidad de Jaén, 2018.

Melosi, Martin V. Precious Commodity. Providing Water for America's Cities. Pittsburgh: University of Pittsburgh Press, 2011.

. The Sanitary City. Urban Infrastructure in America from Colonial Times to the Present. Baltimore / London:The John Hopkins University Press, 2000.

Mitchell, Don. Cultural Geography. A Critical Introduction. Londres: Blackwell Publishing, 2000.

Newcomer, Daniel. “The Symbolic Battleground:The Culture of Modernization in 1940s León, Guanajuato". Mexican Studies / Estudios Mexicanos 18.1 (2002): 61-100.

Oriol Nel.Lo y Francesc Muñoz. “El proceso de urbanización”. Geografía humana. Procesos, riesgos e incertidumbres en un mundo globalizado. Coord. Joan Romero. Barcelona: Ariel, 2007.

Salazar Sánchez, Antonio. El Aguascalientes de antaño (1920-1960). México: Instituto Cultural de Aguascalientes, 2003.

Salmerón Castro, Fernando I. Intermediarios del progreso. Política y crecimiento urbano en Aguascalientes. México: Instituto Cultural de Aguascalientes / Centro de Investigaciones y Estudios Superiores en Antropología Social, 1998.

Schott, Dieter y otros. Resources of the City: Contributions to an Environmental History of Modern Europe. Abindgdon, Oxon: Routledge, 2016.

Suárez Cortez, Blanca Estela. Coord. Historia de los usos del agua en México. Oligarquías, empresas y ayuntamientos (1840-1940). México: Comisión Nacional del Agua / Centro de Investigaciones y Estudios Superiores en Antropología Social / IMTA, 1998. 